\title{
A case of status epilepticus developed after Alpha Lipoic Acid intake
}

\author{
Gürbüz Akçay ${ }^{1}$, Olcay Güngör ${ }^{2}$, Halil Kocamaz ${ }^{3}$, Bedirhan Günaydin ${ }^{4}$ \\ 1 Pamukkale University, Faculty of Medicine, Pediatric Intensive Care Unit, Denizli, Turkey \\ 2 Pamukkale University, Faculty of Medicine, Pediatric Neurology Clinic, Denizli, Turkey \\ 3 Pamukkale University, Faculty of Medicine, Pediatric Gastroenterology Clinic, Denizli, Turkey \\ ${ }^{4}$ Pamukkale University, Faculty of Medicine, Pediatric Clinic, Denizli, Turkey
}

*Corresponding Author: Gürbüz AKÇAY, Assistant Prof., Pamukkale University, Faculty of Medicine, Pediatric Intensive Care Unit, Denizli, Turkey, Email: gurbuzakcay@hotmail.com

\section{Abstract}

Introduction: Alpha Lipoic Acid (ALA) is an antioxidant used in diabetic neuropathy. It is not prescribed to children. However, rarely, intoxication may occur due to accidental or suicidal intake. Case report: A 16-month-old child presented with confusion after taking 1800 mg of ALA. Convulsions that did not respond to midazolam and levetiracetam started in the emergency room. He was admitted to the intensive care unit and was intubated. Convulsions could be controlled with intravenous Ketamine infusion. He received mechanical ventilation support for five days. Gastrointestinal bleeding developed during follow-up and was treated with pantoprazole. There were laboratory measurements consistent with metabolic acidosis. Central nervous system imaging and cerebrospinal fluid examinations were normal. Electroencephalograms taken under elective conditions were reported as normal for his age. He was discharged on the twelfth day of his hospitalization. Conclusion: Children and adults with suspected ALA intake should be referred to tertiary healthcare facilities as soon as possible. In the first stage, gastric lavage and activated charcoal should be applied. Since there is no specific antidote, it should be prepared to deal with resistant convulsions, metabolic acidosis, and multi-organ failure in addition to general supportive therapy.

\section{Keywords: Alpha-Lipoic Acid, INFANT, Poisoning, Status Epilepticus, Ketamine.}

\section{INTRODUCTION}

Alpha Lipoic acid (ALA) is an antioxidant-effective drug [1]. Reactive oxygen and nitrogen oxide species are produced as byproducts of oxidative metabolism. Its main functions have been reported as an immunological host defense. However, it has potential damage to high levels of cellular macromolecules. ALA has the ability to directly reduce free radicals ${ }^{[2]}$. It is mainly used in diabetic neuropathy patients because of this feature ${ }^{[3]}$. Also, there are studies suggesting that it should be used for breast cancer, after spinal cord injury and to reduce the side effects of chemotherapy drugs ${ }^{[4]}$. We have been able to reach seven cases reported so far regarding the rare ALA intoxication [5-11]. We report a rare case with ALA intoxication.

\section{CASE REPORT}

A 16-month-old male patient was presented to our emergency department with a complaint of taking 3 ALA tablets of $600 \mathrm{mg}$, 3 hours ago. It was learned that from the referral form, he was presented to the emergency department of the external center with confusion in the first hour, $1 \mathrm{mg} / \mathrm{kg}$ activated charcoal was administered there, $5 \mathrm{mg}$ rectal diazepam was given for his tonic-clonic convulsion lasting 15-20 seconds and referred to us for further follow-up. He was no history of trauma or convulsion, and his mother had epilepsy. When the patient was admitted, $\mathrm{O}_{2}$ saturation was measured at $100 \%$, heart rate $160 / \mathrm{min}$, body temperature $36.7 \mathrm{C}$ and arterial blood pressure $110 / 70 \mathrm{mmHg}$.

Athetoid involuntary movements began in four extremities at the first hour of admission. Meanwhile, no saturation change was observed. After continuing for more than a minute, $0.1 \mathrm{mg} / \mathrm{kg}$ midazolam was administered intravenously. Due to his involuntary movements did not stop, midazolam infusion was started at $0.07 \mathrm{mg} / \mathrm{kg} / \mathrm{hour}$ and the child was admitted to the intensive care unit. Since his convulsions did not stop, the midazolam infusion rate was increased to $0.1 \mathrm{mg} / \mathrm{kg} /$ hour, but it 
Blood pH 7.19, pCO2 $32.4 \mathrm{mmHg}$, and HCO3 $12.2 \mathrm{mmol} / \mathrm{L}$ were measured, consistent with metabolic acidosis. The INR test result was 1.57 , so five $\mathrm{mg}$ Vitamin $\mathrm{K}$ was administered intravenously. Other laboratory values include blood glucose
3.2-5.7), Troponin 39.8 (n 0-14). WBC $22.59 \mathrm{~K} / \mathrm{uL}$, NEU\% 77.6, HGB 12.4 gr/dL, MCV 57.0, D-Dimer 275 (n 0-243), Fibrinogen $181 \mathrm{mg} / \mathrm{dL}$ (n 200-393), PTZ (Second) 18.5 (n 10.2-14.4), PTZ (INR) 1.57 was measured abnormally compared to the reference values. Other tests were normal (Table 1).

Table 1: Laboratory values of the case by days.

\begin{tabular}{|c|c|c|c|c|c|c|c|c|c|c|}
\hline Laboratory Data & 1 Day & 2 Day & 3 Day & 4 Day & 5 Day & 6 Day & 7 Day & 8 Day & 9 Day & Normal Values \\
\hline Glucose & 209 & $56-92$ & $145-86$ & $111-127$ & 127 & 98 & 99 & 88 & 96 & $60-100 \mathrm{mg} / \mathrm{dL}$ \\
\hline $\mathrm{pH}$ & 7.194 & $7.376-7.34$ & $7.452-7.255$ & $7.426-7.45$ & 7.34 & 7.468 & 7.385 & 7.387 & 7.40 & 7.3507 .450 \\
\hline $\mathrm{HCO} 3$ (std) & 12.6 & 14.4-19.7 & $21-18.5$ & 23.1 & 22.3 & 23.9 & 22 & 23.1 & 24.9 & $21-29 \mathrm{mmol} / \mathrm{L}$ \\
\hline $\mathrm{CO} 2$ & 32.4 & $17.1-45$ & 35.1 & 28.2 & 43.8 & 34.8 & 37.3 & 40.4 & 41.6 & 35- $45 \mathrm{mmHg}$ \\
\hline Lactate & 7.7 & 1.62 & 1.29 & - & - & 1.34 & 1.22 & 1.32 & & $0.7-2.1 \mathrm{mmol} / \mathrm{L}$ \\
\hline WBC & 22.59 & 15.41 & 20.14 & 14.89 & 17 & 10.66 & 13.37 & 12.09 & 9.95 & 4- $10 \mathrm{~K} / \mathrm{uL}$ \\
\hline HGB & 12.4 & 12 & 11.8 & 7 & $10.6-13.9$ & 12.9 & 12.4 & 11.9 & & $11-16 \mathrm{gr} / \mathrm{dL}$ \\
\hline PLT & 458 & 339 & 300 & $204-142$ & 187 & 199 & 284 & - & 572 & $150-300 \times 1000 / \mathrm{mm} 3$ \\
\hline INR & 1.57 & 1.51 & 1.46 & 1.38 & 1.14 & - & - & - & - & $0.85-1.2$ \\
\hline Troponin & 39.8 & 8.64 & 10.4 & - & - & - & - & - & - & $0-14 \mathrm{ng} / \mathrm{mL}$ \\
\hline D-DIMER & 273 & 268 & 193 & - & - & - & - & - & - & $0-243 \mathrm{ng} / \mathrm{mL} \mathrm{DDU}$ \\
\hline AST & 33 & 49 & 46 & 90 & 107 & 115 & 59 & 45 & 33 & $\mathrm{IU} / \mathrm{L}<32$ \\
\hline$\overline{A L T}$ & 16 & 23 & 28 & 60 & 72 & 95 & 70 & 59 & 44 & $\mathrm{IU} / \mathrm{L}<33$ \\
\hline Vitamin B12 & & 743 & & & & & & & & $>200 \mathrm{ng} / \mathrm{L}$ \\
\hline Urine ketone & ++ & + & + & & & & & & & \\
\hline Urine Glucose & ++++ & & & & & & & & & \\
\hline Urine protein & & & + & & & & & & & \\
\hline Urine hemoglobin & & & +++ & & & & & & & \\
\hline CSF Glucose & & & 68 & & & & & & & $\mathrm{mg} / \mathrm{dL}(45-80$ mg/DI) \\
\hline CSF Protein & & & 16 & & & & & & & $\mathrm{~g} / \mathrm{L}(\mathrm{n}: 20-40 \mathrm{mg} / \mathrm{dL})$ \\
\hline CSF culture & & & & & negative & & & & & \\
\hline CSF PCR & & & & negative & & & & & & \\
\hline Blood culture & & & & & & & negative & & & \\
\hline Urine culture & & & negative & & & & & & & \\
\hline
\end{tabular}

Abnormal values are marked in bold. CSF: Cerebro Spinal Fluid

National Poison Information Center (number 114) was consulted. It was reported that there was no specific treatment or antidote. Cardiac monitoring, symptomatic treatment, and asymptomatic 24-hour follow-up was recommended. Since the patient continued to have convulsions while receiving the midazolam infusion, an IV loading of levetiracetam $20 \mathrm{mg} / \mathrm{kg}$ was performed, and maintenance was initiated at $20 \mathrm{mg} / \mathrm{kg} / \mathrm{day}$. Because of his convulsions, tachycardia, and bad clinical condition progressed, the patient was accepted as status epilepticus and was intubated. Although midazolam was increased to $2 \mathrm{mg} / \mathrm{kg} / \mathrm{hour}$, his convulsion did not stop. Then, ketamine was started at a dose of $10 \mathrm{mcg} / \mathrm{kg} / \mathrm{minute}$ and the convulsion was controlled. Contrast-enhanced and diffusion cranial MRI was performed to exclude encephalitis and increased intracranial pressure. No pathology was found in the MRI. The urine toxicology test was negative.
On the second day, the patient was followed up on mechanical ventilation. His metabolic acidosis continued with blood $\mathrm{pH} 7.33$, pCO2 $20 \mathrm{mmHg}$, and $\mathrm{HCO} 310 \mathrm{mmol} / \mathrm{L}$. Fluid therapy was set at $2000 \mathrm{cc} / \mathrm{m} 2 /$ day and $\mathrm{NaHCO}_{3}$ administration was continued until the blood $\mathrm{HCO} 3$ level recovered. Nifedipine treatment was given because the arterial blood pressure was above the 99 percentiles. In follow-up examinations, blood leukocyte, glucose, electrolyte, and troponin values improved.

On the third day, the patient was followed up on mechanical ventilation. $C$ Reactive protein increased above normal values with $8.08 \mathrm{mg} / \mathrm{L}(\mathrm{n}<5)$. The INR value decreased compared to the previous day. Lumbar puncture was performed due to the patient's persistent fever that rose to 38 degrees. Cerebrospinal fluid (CSF) biochemistry was normal. No cells were seen in the direct and stained examination. No grow was detected in the 
urine culture. It was planned to discontinue the patient's midazolam dose by reducing it. In the complete urinalysis, glucose was lost, ketone + persistence, and + leukocyturia, +++ hemoglobinuria, and + proteinuria started.

He was followed up on mechanical ventilation on the fourth day. Hemoglobin was measured as $7 \mathrm{~g} / \mathrm{dL}$, then $15 \mathrm{cc} / \mathrm{kg}$ erythrocyte replacement therapy was given. Midazolam was discontinued on the fifth day. Ketamine treatment was halved at $5 \mathrm{mcg} / \mathrm{kg} / \mathrm{min}$. CSF culture was reported as negative. Hemoglobin was measured as $10.7 \mathrm{~g} / \mathrm{L}$, but because of active lower gastrointestinal (GIS) bleeding, erythrocyte replacement was performed again. Omeprazole $2 \mathrm{mg} / \mathrm{kg} /$ day IV 24-hour infusion was initiated. In biochemistry tests, AST increased by $90 \mathrm{U} / \mathrm{L}$, and ALT increased by $60 \mathrm{U} / \mathrm{L}$. Occult blood was positive, and rare erythrocytes and leukocytes were found in the stool. He has been melaena three times. The patient's response to the painful stimulus in the form of spontaneous eye opening and crying was observed for a short time. Mechanical ventilation was stopped and extubated.

On the sixth day of his hospitalization, he started responding to verbal stimuli. Enteral feeding was initiated after GIS bleeding stopped. The omeprazole dose was cut in half. He was transferred to the general children's service. On the twelfth day of his first admission, he was discharged with a prescription of omeprazole 1 x10 mg/day and levetiracetam $20 \mathrm{mg} / \mathrm{kg} /$ day.

On the twentieth day after the first admission and in the third month, 18-channel bipolar, longitudinal, transverse, and reference montage, digital EEG recordings reported the as compatible with the age and normal, and antiepileptics were discontinued.

\section{DISCUSSION}

Intoxication of 4 children ${ }^{[7,8,10,11]}$ and 3 adults ${ }^{[5,6,9]}$ has been reported in the literature up to date. Our case was in a status epilepticus similar to the previous pediatric cases, his seizure did not respond to classical anticonvulsants and, unlike the previous cases, be stopped with ketamine infusion.

It has been reported that ALAs which was accidentally taken by pediatric patients, belongs to an adult diabetic patient at home ${ }^{[8,}$ 10, 11]. One adolescent and 3 adult patients were exposed to suicide purposes and one patient was exposed to toxication because of prescribing error ${ }^{[5-7,9]}$.

One case reported as fatal. She was suspected of taking norfenefrine and paracetamol in addition to ALA. However, since the paracetamol level is low and the toxicity of norfenephrine has not been reported, multi-organ failure has been attributed to ALA ${ }^{[7]}$. All other cases were discharged without any sequelae.

There are no human studies on the toxic dose of ALA. In a study conducted in the rhesus monkey liver, the $\mathrm{LD}_{50}$ dose was reported as $90-100 \mathrm{mg} / \mathrm{kg}{ }^{[12]}$. In another study conducted by Fuke et al. with rats, they determined the LD50 dose as 1320 $\mathrm{mg} / \mathrm{kg}$ in male rats and $1130 \mathrm{mg} / \mathrm{kg}$ in female rats ${ }^{[13]}$. Cremer et al reported the $L_{50}$ dose $>2000 \mathrm{mg} / \mathrm{kg}$ in their study with Wistar rats ${ }^{[14]}$. In our case (body weight $10.8 \mathrm{~kg}$ ), the dose taken was $166.66 \mathrm{mg} / \mathrm{kg}$. In the case reported by Karaarslan et al. of similar age, the amount of ALA taken was calculated as $226 \mathrm{mg} / \mathrm{kg}$.

The main clinical findings in the cases, a spectrum that starts with loss of consciousness, lethargy, involuntary movements, convulsions, central nervous system findings such as status epitepticus and tachycardia, hyper/hypotension, and progress to multi-organ failure. There are clues that gastric lavage and administration of activated charcoal may be beneficial to patients. As reported by Emir et al., a 22-years-old female patient received $18000 \mathrm{mg}$ of ALA, but activated charcoal was administered within 2 hours and she was discharged healthy after 3 days of intensive care ${ }^{[5]}$. Supportive treatment has been used in all of them. Six of the 7 cases were given diazepam, midazolam, phenytoin, clonazepam, phenobarbitone, levetiracetam, and lorazepam for convulsion treatment in the intensive care unit [5-11]. Despite those anticonvulsants, refractory convulsions have been controlled with thiopental sodium in one patient and propofol in another patient $[9,11]$. We could control the refractory convulsion with ketamine infusion in our case. There is no known direct antidote for ALA toxication. However, in the study of Martin E. GAL (1965), the mortality rate was found to be lower in rats that were given toxic doses of ALA together with thiamine (Vitamin B1) compared to those who were not given (0\% vs $75 \%)^{[15]}$. Since cases presenting with ALA toxication are noisy, Brain Computed Tomography (CT) was performed in most cases and Brain Magnetic Resonance Imaging (MRI) was performed in one case to exclude intracranial pathology. However, all of them were normal [5, 8-11].

The reason that ALA causes neurological symptoms has been attributed to its ability to easily cross the blood-brain barrier ${ }^{[5,16]}$. In some cases, reported previously, lactate was found high, as in our case ${ }^{[6,7,11]}$. In a study conducted in the rhesus monkey liver, they shown that high-dose intravenous ALA caused edema and deterioration in vital membranes in mitochondria. ${ }^{[12]}$ We can explain it as the inadequate oxidative phosphorylation as a result of the damage to the mitochondria and the conversion of the produced pyruvic acid to lactate.

Data on chronic intoxication of ALA are also rare. Ridruejo et al. reported ALA-induced Acute Cholestatic Hepatitis in a 63-yearsold case, but they did not report a hypothesis about its pathogenesis [17]. As can be seen in Table 1, liver function tests (LFT) (AST, ALT) were increased in our case. Similar findings have been seen in the previous studies ${ }^{[6,10]}$.

In the experimental monkey study, obvious structural deterioration in the liver was reported with the ALA toxicity [12]. The increase in INR in the cases is also remarkable [6,7,9]. In our case, the INR was high up to the 5th day and gastrointestinal bleeding was observed together. In the case of Hadzik et al, it increased to 6.4 in the 7 th hour. At the same time, their LFTs have increased 6 times. It is the only case of death in the literature ${ }^{[7]}$.

Our case's EEG was normal at 20th days and 3rd months after his first admission. None of the previously reported cases have 
EEGs taken in the acute period ${ }^{[8,11]}$. Performing an EEG in the acute period with ALA intoxication may enable us to better understand the convulsion type of the cases.

\section{CONCLUSION}

Adults should keep this drug in protected places. Children and adults with suspected ALA intake should be referred to a tertiary care institution as soon as possible. In the first step, gastric lavage and activated charcoal should be applied. Since ALA does not have a specific antidote, it should be prepared to deal with resistant convulsions, metabolic acidosis, and multi-organ failure in addition to general supportive treatment. New and multi-center studies are needed for the subject to be fully understood.

\section{Disclosure}

Declarations of interest: None

\section{Conflict of Interest:}

There is no conflict of interest between the authors who wrote this article.

\section{REFERENCES}

1. Biewenga GP, Haenen GR, Bast A. The pharmacology of the antioxidant lipoic acid. General Pharmacology: The Vascular System. 1997; 29(3):315-31.

2. Moini H, Packer L, Saris N-EL. Antioxidant and prooxidant activities of $\alpha$-lipoic acid and dihydrolipoic acid. Toxicology and applied pharmacology. 2002; 182(1):84-90.

3. Reljanovic M, Reichel G, Rett K, Lobisch M, Schuette K, Möller W, et al. Treatment of diabetic polyneuropathy with the antioxidant thioctic acid ( $\alpha$-lipoic acid): a two year multicenter randomized double-blind placebo-controlled trial (ALADIN II). Free radical research. 1999; 31(3):171-9.

4. Ergene E. Alfa Lipoik Asit Ve Metabolik Etkileri Üzerine Bir Araştirma. Adnan Menderes Üniversitesi Sağlık Bilimleri Fakültesi Dergisi. 2(3):159-65.

5. Emir DF, Ozturan IU, Yilmaz S. Alpha lipoic acid intoxicatıon: An adult. The American journal of emergency medicine. 2018; 36(6):1125. e3-. e5.

6. Gulen M, Simsek Y, Oner E, Satar S. First description of the alpha lipoic acid intoxication in an adult patient worldwide following oral administration. The American journal of emergency medicine. 2018; 36(6):1126. e5-. e6.

7. Hadzik B, Grass H, Mayatepek E, Daldrup T, Hoehn T. Fatal nonaccidental alpha-lipoic acid intoxication in an adolescent girl. Klin Padiatr. 2014; 226(05):292-4.

8. Karaarslan U, İşgüder R, Bağ Ö, Kışla M, Ağın H, Ünal N. Alpha lipoic acid intoxication, treatment and outcome. Clinical Toxicology. 2013; 51(6):522-.

9. Moretti R, Angeletti C, Minora S. Multiple organ failure and shock following acute alpha lipoic acid (ALA) intoxication. Clinical Toxicology. 2019; 57(8):749-51.

10. Özçetin M, Yilmaz R, Tetikçok R, Karaaslan E, Dürer Z, Narin B. On Aylik Çocukta Alfa Lipoik Asit Intoksikasyonu; Olgu Sunumu. Anatolian Journal of Clinical Investigation. 2012; 6(1).

11. Tolunay $O$, Çelik T, Kömür M, Gezgin AE, Kaya MS, Çelik Ü. A rare cause of status epilepticus; alpha lipoic acid intoxication, case report and review of the literature. european journal of paediatric neurology. 2015; 19(6):730-2.

12. Vigil M, Berkson BM, Garcia AP. Adverse effects of high doses of intravenous alpha lipoic acid on liver mitochondria. Global advances in health and medicine. 2014; 3(1):25-7.

13. Fuke H, Iwanami K, Watanabe N, Kumada S. Acute, subacute and chronic toxicities of thioctic acid in rats. Nihon yakurigaku zasshi Folia pharmacologica Japonica. 1972; 68(3):265.

14. Cremer D, Rabeler R, Roberts A, Lynch B. Safety evaluation of $\alpha-$ lipoic acid (ALA). Regulatory Toxicology and Pharmacology. 2006; 46(1):29-41.

15. Gal EM. Reversal of selective toxicity of (-)-a-lipoic acid by thiamine in thiamine-deficient rats. Nature. 1965; 207(4996):535-.

16. Packer L, Tritschler HJ, Wessel K. Neuroprotection by the metabolic antioxidant $\alpha$-lipoic acid. Free radical biology and medicine. 1997; 22(1-2):359-78.

17. Ridruejo E, Castiglioni T, Silva MO. Thioctic acid-induced acute cholestatic hepatitis. Annals of Pharmacotherapy. 2011; 45(7):e43. 